\title{
Sistema descentralizado individual de água não potável: a necessidade da gestão da qualidade e da quantidade
}

\author{
Individual decentralized non-potable water system: the \\ need for quality and quantity management
}

\section{Tiago de Vasconcelos Gonçalves Ferreira Lúcia Helena de Oliveira}

\section{Resumo \\ A}

implantação de sistemas de água não potável em edifícios residenciais está crescendo, tendo em vista a redução dos níveis atuais de demanda de água potável. Esse fato vem ocorrendo mesmo sem o embasamento teórico adequado por meio de normas técnicas, regulamentos ou legislações específicas para o projeto, execução e operação de tal sistema. Nesse sentido, o objetivo deste artigo é avaliar o desempenho qualitativo e quantitativo de um sistema descentralizado individual nas etapas de operação e manutenção. O método utilizado foi o estudo de caso. Para tal, foram realizadas a caracterização do sistema e a coleta de informações de usuários. Os resultados mostram que o sistema de água não potável, além de não ter apresentado um impacto de redução no consumo de água, propiciou um surto de infecção gastrointestinal para a população do edifício, devido à falta de capacitação dos profissionais envolvidos em todas as etapas do sistema e, em especial, na etapa de operação e manutenção, o que afetou a saúde dos usuários. Conclui-se que a capacitação profissional para executar, operar e manter o sistema de água não potável é indispensável para garantir a eficiência no sistema e preservar a saúde dos usuários.

Palavras-chave: Água não potável. Sistema descentralizado. Sistema individual.

\section{Abstract}

The deployment of non-potable water systems in residential buildings is growing in view of the need to reduce the current demand for drinking water. This has been occurring even without adequate theoretical basis through technical standards, regulations or specific legislation on the design, implementation and operation of such systems. With this in mind, the aim of this paper is to assess the qualitative and quantitative performance of an individual decentralized system in the operation and maintenance stages. The method used was the case study. Hence,

Tiago de Vasconcelos Gonçalves Ferreira Universidade de São Paulo São Paulo - SP - Brasil

Lúcia Helena de Oliveira Universidade de São Paulo São Paulo - SP - Brasil

Recebido em 18/05/16 Aceito em 06/01/17 we characterised the system and collected information from users. The results show that the non-drinking water system, in addition to not having an impact on the reduction of water consumption, led to an outbreak of gastrointestinal infection among the population of the building. This fact occurred due to the lack of training of the professionals involved in all stages of the system, particularly in the operation and maintenance phase, which affected the health of users. It is concluded that professional training to run, operate and maintain non-potable systems is essential to ensure the systems' efficiency and to preserve the health of users.

Keywords: Non-potable water. Decision-making. Decentralized system. Centralized system. 


\section{Introdução}

A escassez de água em áreas urbanas tem estimulado a implantação de sistemas de água não potável em edifícios residenciais. Esses sistemas têm sido projetados, executados e operados sem o embasamento teórico adequado, quer seja por norma técnica, regulamento ou legislação específica. Nesse contexto, a adoção de água não potável em edifícios residenciais apresenta um panorama com poucos profissionais capacitados para projetar, executar, operar e manter o sistema; órgãos públicos não preparados para aprovar e fiscalizar a implantação desses sistemas; carência de legislação e normalização específica; e desconhecimento de tais tecnologias pelos usuários.

As tecnologias disponíveis para o tratamento de água não são o principal obstáculo para a implementação de sistema de água não potável em edifícios, mas sim a gestão desse sistema, de modo a reduzir a ocorrência de falhas e, portanto, garantir a segurança do uso da água sem colocar em risco a saúde dos usuários. Essas tecnologias, uma vez instaladas em edifício, interagem com o sistema de água potável e, por isso, dependem de uma gestão adequada e permanente para propiciar um uso seguro (DIMITRIADES, 2005; OLIVEIRA, 2009).

Outra questão relacionada aos sistemas prediais individuais de água não potável é a possibilidade de maior consumo de energia, o que implica maiores emissões de gases de efeito estufa e maiores custos para implantação do que um sistema centralizado que atenda a vários edifícios. Os sistemas de água não potável em edifícios residenciais vêm sendo implantados sem uma avaliação dos custos ambientais, sociais e econômicos de modo mais abrangente.

Nesse sentido, o objetivo deste artigo é avaliar o desempenho quantitativo, no que se refere ao impacto de redução do consumo potável, e o desempenho qualitativo, no que se refere ao controle da qualidade da água potável, de um sistema descentralizado individual de água não potável de um edifício residencial nas etapas de operação e manutenção.

\section{Sistema predial de água não potável}

O sistema predial de água apresenta dois subsistemas de água: potável e não potável, conforme ilustrado na Figura 1. Considera-se água não potável qualquer água que não atenda ao padrão de potabilidade (BRASIL, 2011). Desse modo, são tipos de água não potável para edifícios residenciais a água pluvial, a água residual e a água subterrânea, após tratamento.

Figura 1 - Sistema predial de água em edifício residencial

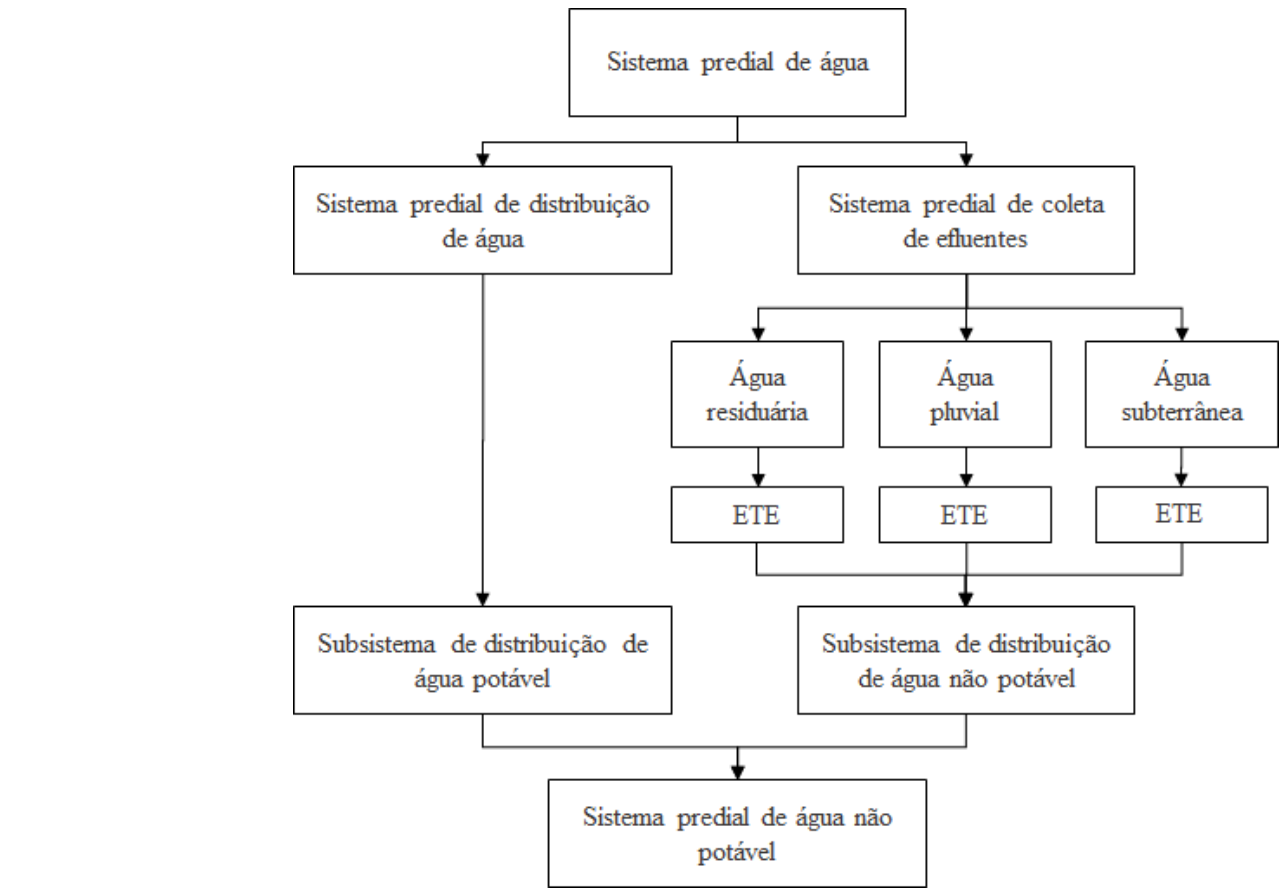

Fonte: Oliveira e Marques (2013). 
Essas características do sistema de água não potável o tornam mais vulnerável a um risco de contaminação do que um sistema convencional de água potável, em que só circula água potável nos reservatórios e em todos os pontos de utilização. Para enfatizar esse aspecto vários trabalhos nacionais e internacionais discutem o potencial de perigo à saúde dos usuários associado com a contaminação microbiológica de água cinza (DIXON; BUTLER; FEWKES, 1999; PEIXOTO, 2008; SCHEE, 2004)

Na Figura 2 são apresentados os tipos de sistemas de água não potável segundo a fonte geradora de água e possíveis aplicações em edifícios residenciais, propostos por Oliveira e Marques (2013).

A partir das diferentes fontes de água não potável as autoras apresentam a classificação dos seguintes tipos de sistemas prediais de água não potável para edifícios residenciais:

(a) sistema predial de água não potável recuperada (SPANP-R);

(b) conjunto de tubulação, reservatórios, equipamentos e outros componentes destinados a coletar água cinza ou negra, armazenar, tratar e distribuir a água cinza ou negra tratada, cujo objetivo é reduzir tanto a demanda de água potável como o volume de esgoto destinado ao sistema de coleta, transporte e tratamento de esgoto sanitário;

(c) sistema predial de água não potável - pluvial (SPANP-P);

(d) conjunto de tubulação, reservatórios, equipamentos e outros componentes destinados a coletar água pluvial, armazenar, tratar e distribuir a água pluvial tratada, cujo objetivo é reduzir tanto a demanda de água potável da rede pública ou privada como amortecer as vazões no sistema de drenagem urbana; (e) sistema predial de água não potável subterrânea (SPANP-S); e

(f) conjunto de tubulação, reservatórios, equipamentos e outros componentes destinados a coletar água subterrânea, armazenar, tratar e distribuir a água subterrânea tratada, com o objetivo de reduzir a demanda de água potável da rede pública ou privada.

\section{Sistemas centralizados e descentralizados}

Considerando-se a logística de localização de estações de tratamento de efluentes (ETE) em relação ao edifício e com base nos conceitos de sistemas de tratamento de esgoto sanitário, os sistemas de água não potável podem ser denominados descentralizados e centralizados.

Nos sistemas descentralizados as águas residuais de uma casa ou de um edifício são coletadas, tratadas e reutilizadas ou dispostas no próprio local ou próximo ao ponto de geração. Por outro lado, nos sistemas centralizados de água não potável (Figura 3) as águas residuais provenientes de vários edifícios são coletadas e transportadas para um único local e, em seguida, são tratadas e distribuídas aos mesmos edifícios ou a outros edifícios para utilização (UNITED..., 2004; DIMITRIADIS, 2005; SHEHABI; STOKES; HORVATH, 2012).

Os sistemas descentralizados são denominados individuais quando atendem a um único edifício (Figura 4), e descentralizados em grupo (Figura 5) quando atendem a um conjunto de edifícios como, por exemplo, de um condomínio, de uma quadra ou de um bairro. Observa-se que os sistemas descentralizados em grupo podem ser considerados um tipo de sistema centralizado.

\section{Figura 2 - Sistemas prediais de água não potável com diferentes fontes e usos no edifício residencial}

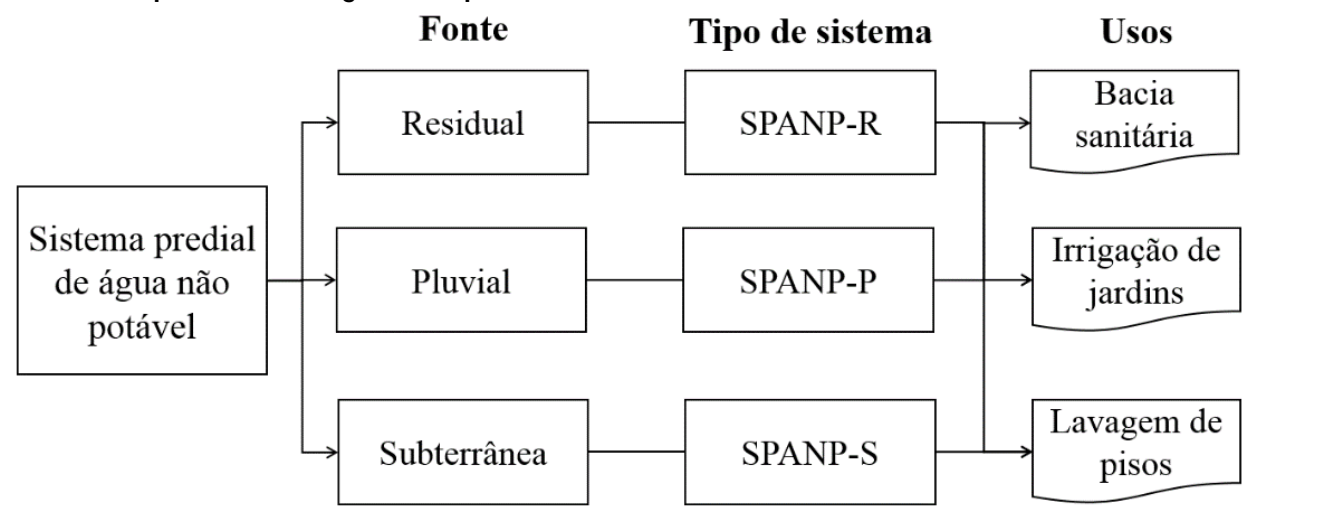

Fonte: Oliveira e Marques (2013). 
Figura 3 - Sistema centralizado de água não potável

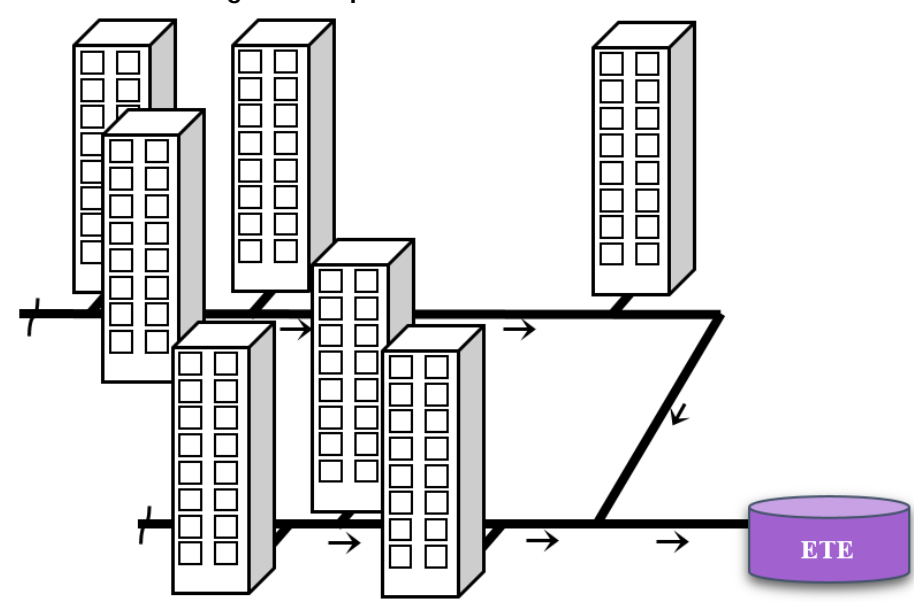

Figura 4 - Sistemas descentralizados individuais de água não potável

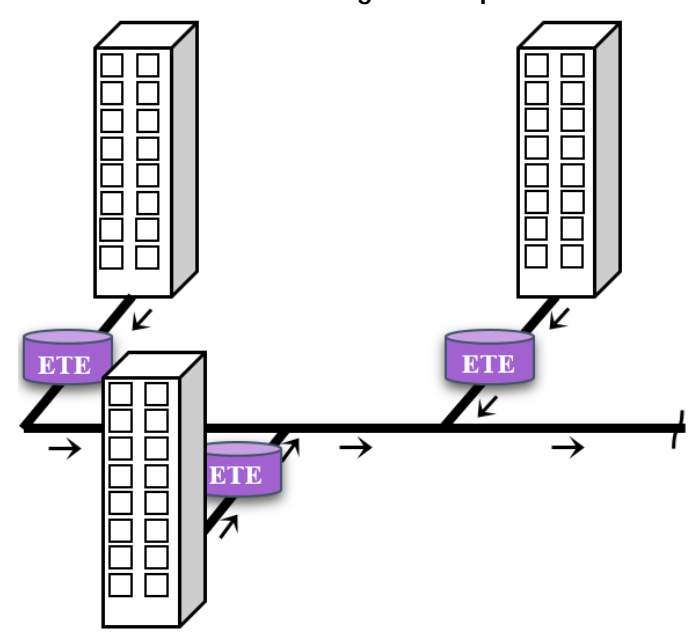

Figura 5 - Sistemas descentralizados em grupos de água não potável

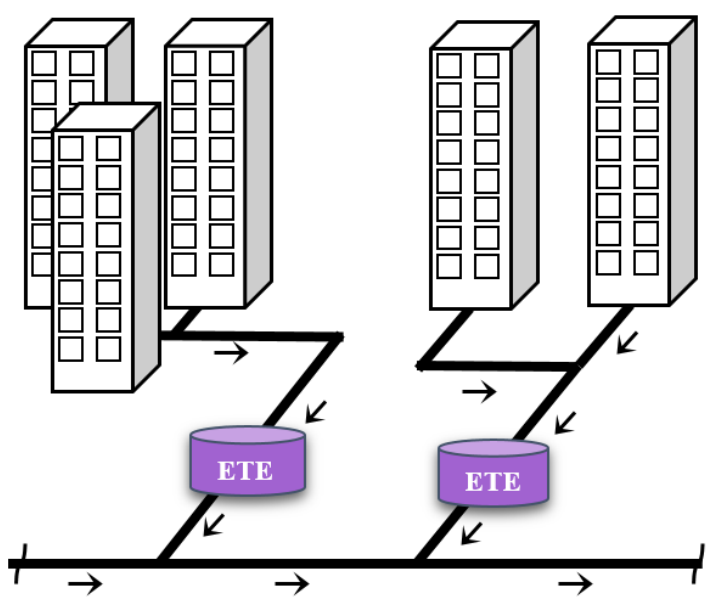

Existem diversos fatores sociais, ambientais e econômicos envolvidos na tomada de decisão para a implantação dos sistemas descentralizados. Dimitriadis (2005) constatou que há um equívoco comum na afirmação de que os sistemas descentralizados representam uma forma de suprimento de água de baixo custo; entretanto, a garantia de retorno financeiro de um sistema desse porte envolve o estudo de diversas variáveis de implantação e de operação. Nesse sentido, 
Hernández et al. (2006) comentam que, em geral, as metodologias existentes para avaliação da viabilidade para utilização de água não potável são focadas apenas na análise de custos, sem levar em consideração alguns impactos ambientais e sociais que o sistema está sujeito, como os riscos biológicos e químicos, contaminação da água, dentre outros.

No Reino Unido, a Environment Agency (2011) concluiu que os sistemas centralizados evitam muitos problemas relacionados aos sistemas descentralizados individuais. Eles podem oferecer maior equilíbrio entre oferta e demanda, qualidade da água superior, maior confiabilidade do sistema, uma vez que possibilitam melhor manutenção e redução de custos. O consumo de energia também pode ser reduzido pela instalação de bombas mais adequadas e processos de tratamento mais eficientes.

Os impactos ambientais devem ser avaliados quando do projeto de sistemas descentralizados individuais. Um estudo realizado por Shehabi, Stokes e Horvath (2012) analisou dois sistemas em operação atualmente na Califórnia, EUA: um descentralizado individual e um centralizado. Os pesquisadores concluíram que as economias de escala do sistema centralizado geram um impacto ambiental de um quinto do que se verifica nos sistemas descentralizados individuais, para o mesmo volume tratado. Além disso, o sistema centralizado reduz a emissão de gases de efeito estufa, devido à maior facilidade de queima do metano $\left(\mathrm{CH}_{4}\right)$ gerado no processo de tratamento e de sua utilização para a geração de energia, enquanto este é diretamente emitido para a atmosfera pelos sistemas individuais.

Ainda com relação aos gases de efeito estufa, Shimizu, Dejima e Toyosada (2013), ao pesquisar as emissões de dióxido de carbono $\left(\mathrm{CO}_{2}\right)$ em edifícios com sistemas de água não potável recuperada no Japão, concluíram que elas são 62\% maiores em relação aos sistemas convencionais.

Os edifícios no Brasil apresentam sistemas de suprimento de água do tipo indireto com reservatórios inferior e superior. Assim, esse tipo de sistema solicita uma demanda de energia para recalque, tanto de água potável como de não potável, que pode implicar maior consumo de energia. Some-se a essa parcela a energia necessária ao tratamento de esgoto.

A eletricidade gerada de hidrelétricas e de termelétricas emite uma grande quantidade de dióxido de carbono $\left(\mathrm{CO}_{2}\right)$ e de metano $\left(\mathrm{CH}_{4}\right)$ para a atmosfera (FEARNSIDE, 2016; BRASIL, 2007). Observa-se ainda que a decomposição da matéria orgânica nas estações de tratamento de esgoto gera o metano $\left(\mathrm{CH}_{4}\right)$, outro gás de efeito estufa. Nesse sentido, pode-se afirmar que os SPANP contribuem para o aumento das emissões de gases de efeito estufa.

Com relação ao gerenciamento do sistema observa-se que apesar de mais criterioso, o gerenciamento de um sistema centralizado pode ser mais econômico, pois o custo de contratação de uma equipe capacitada e fixa é menor do que o custo de contratação de várias equipes individuais terceirizadas, uma para cada sistema individual. Segundo Hernández et al. (2006), o número de profissionais exigidos depende do desenho da planta, da complexidade do tratamento e do nível de automatização.

Outro aspecto a ser considerado são as barreiras relacionadas à implementação de sistemas de água não potável. Parsons et al. (2010), em estudo realizado no Reino Unido sobre aproveitamento de água pluvial, concluíram que a falta de legislação que regulamenta o uso de água não potável pluvial é uma barreira que dificulta a implantação desses sistemas.

O sistema de água não potável - recuperada pode ter um papel significativo na redução do consumo de água total de água potável, fornecida pela concessionária, que contribui para o uso mais sustentável. No entanto, pode representar riscos para a saúde e causar efeitos estéticos negativos, especialmente em regiões de climas quentes, onde altas temperaturas ambientes podem aumentar a degradação de matéria orgânica e, consequentemente, o crescimento do patógeno. Isso implica que sistemas de água não potável descentralizada individual requer sistemas de transporte, armazenamento e tratamento muito eficientes e confiáveis (FRIEDLER; KOVALIO; GALIL, 2005).

Enfim, são vários os aspectos relacionados à sustentabilidade que devem ser avaliados quando da decisão pela implantação de sistemas prediais individuais de água não potável, além da redução do consumo de água, que também pode não ocorrer.

\section{Método}

O método adotado é o estudo de caso de um sistema de água não potável tendo como fontes a água recuperada, a pluvial e a subterrânea em um edifício residencial, em que diversos fatores como capacitação de profissionais de operação e procedimentos de manutenção influenciam o atendimento ao requisito de desempenho “segurança ao uso da água”.

A pesquisa foi desenvolvida nas seguintes etapas: 
(a) levantamento das características físicas e funcionais do edifício;

(b) caracterização do sistema de água não potável: tubulações, sistema de tratamento e sistema de reservação;

(c) coleta de informações de usuários por meio de entrevistas e, em especial, do zelador do condomínio no que se refere aos procedimentos de operação e manutenção, bem como para evitar a contaminação da água potável;

(d) coleta de dados relativos à qualidade da água potável; e

(e) coleta de dados e informações no que se refere aos indicadores de consumo de água em quatro fases distintas, em função dos tipos de fontes de água, para a análise dos impactos de redução do consumo.

Após a análise de toda a documentação referente ao uso e operação do condomínio, foi possível classificar a série histórica de consumo em diferentes fases, em função do tipo de fonte de abastecimento dos sistemas de distribuição de água potável e não potável. No total foram quatro fases, quais sejam:

(a) fase 1: sem sistema de água não potável recuperada, de janeiro/2009 a junho/2010;

(b) fase 2: com sistema de água não potável recuperada, de julho/2010 a maio/2014;

(c) fase 3: sem sistema água não potável recuperada, de junho/2014 à novembro/2014; e

(d) fase 4: sem sistema de água não potável recuperada, mas com sistema de água não potável subterrânea e pluvial, de dezembro/2014 até no momento. Observa-se que as águas subterrânea e pluvial não receberam nenhum tratamento e foram adicionadas diretamente ao reservatório.
Todos os dados referentes ao consumo de água potável foram obtidos da base de dados da Companhia de Saneamento Básico do Estado de São Paulo (COMPANHIA..., 2016).

\section{Resultados e discussão}

A caracterização do condomínio, a descrição do sistema de água não potável, a exposição do problema de contaminação ocorrido e os impactos de redução do consumo de água potável são apresentados e discutidos a seguir.

\section{Características físicas e funcionais do condomínio}

O condomínio é constituído por duas torres, denominadas: Torre 1 e Torre 2. A Torre 1 dispõe de quinze pavimentos e a Torre 2 dispõe de catorze pavimentos. Em cada um dos pavimentos encontram-se seis unidades habitacionais, excetuando-se o andar térreo, que possui cinco unidades habitacionais por torre. Desse modo, o condomínio estudado possui um total de 184 unidades habitacionais e população estimada de 593 habitantes. A maquete eletrônica do condomínio está apresentada na Figura 6.

O pavimento tipo possui seis unidades habitacionais, e cada uma delas é constituída de três dormitórios, dois banheiros, sala, área de serviço e cozinha, hall de circulação e varanda.

No térreo estão localizados a entrada principal, a área de lazer com piscina, a quadra esportiva, o playground, o salão de festas e as garagens. A estação de tratamento de efluentes do sistema (ETE) de água não potável, indicada na Figura 6, está localizada abaixo do pavimento garagem do subsolo.

Figura 6 - Maquete eletrônica do condomínio residencial

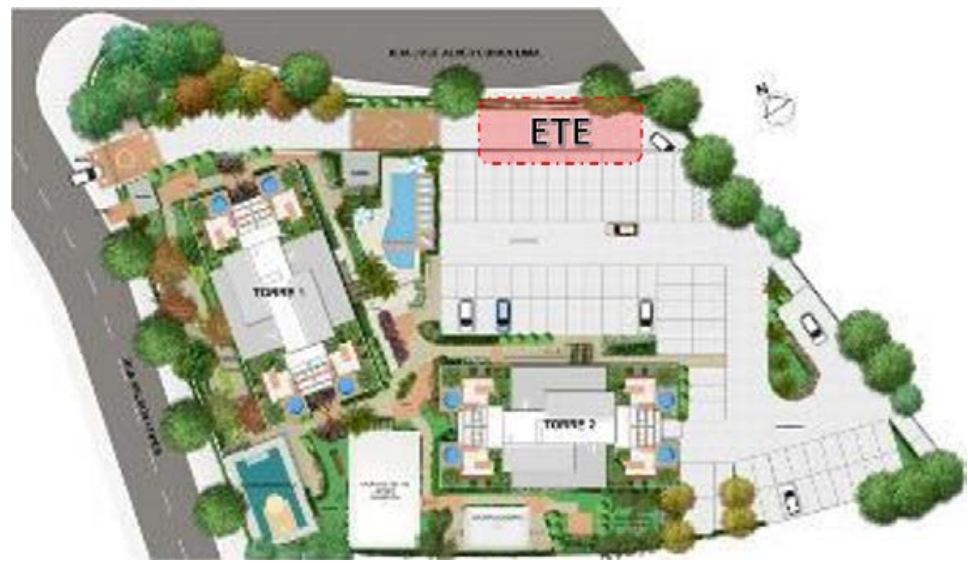

Fonte: acervo do condomínio (2015). 


\section{Sistema de água não potável do condomínio}

O sistema de água não potável do condomínio é descentralizado individual, ou seja, as águas residuais são coletadas, tratadas e utilizadas no próprio local ou próximo ao ponto de geração.

O sistema instalado no condomínio foi projetado para receber efluentes que apresentam baixa carga de matéria orgânica, denominadas água cinza, mais especificamente os efluentes dos chuveiros, lavatórios e máquinas de lavar roupas. Conforme apresentado na Figura 2, trata de um sistema de água não potável - recuperada (SPANP-R).

Embora o sistema tenha sido projetado e executado para água não potável - recuperada, observa-se que a partir de dezembro de 2014 foram acrescentadas as fontes de água pluvial e de água subterrânea.

\section{Sistema de tratamento}

Na Figura 7 estão apresentados, em sequência e operação, os elementos da estação de tratamento de águas cinzas (ETAC) do condomínio estudado. É um sistema compacto de tratamento biológico aeróbio que faz a digestão aeróbia do esgoto por meio de microrganismos. A utilização de rotores semissubmersos, com base em forma de colmeia, e, portanto, grande superfície específica, propicia a formação de biofilme, o que aumenta a eficiência do processo de tratamento.

A operação do sistema ocorre em sete etapas, descritas a seguir.

1 - reservatório de equalização: recebe a água cinza, ou seja, os efluentes dos chuveiros, lavatórios sanitários e das máquinas de lavar roupa. Tem como função regular a vazão dos efluentes antes do tratamento biológico, o que mantém vazão e carga orgânica constante.
2 - decantação primária: após o reservatório de equalização, o efluente é transportado para o reservatório de decantação primária, onde passa lentamente. Isso permite que os sólidos em suspensão de maior densidade sejam sedimentados gradualmente no fundo.

3 - tratamento biológico: nessa etapa, o efluente é submetido a um tratamento por meio de biocilindros, os quais favorecem a formação de biofilmes. O contato direto com o oxigênio do ar, devido ao movimento dos cilindros, otimiza o desempenho das bactérias aeróbicas.

4 - decantação secundária: na sequência, o efluente é conduzido aos reservatórios de decantação secundária, local onde o material, proveniente do tanque de tratamento biológico e já degradado, é decantado sob a forma de lodo.

5 - tanque de acúmulo: após o processo de tratamento, os efluentes são conduzidos a um reservatório intermediário, antes do processo de filtração.

6 - filtração: nessa etapa ocorre a retirada de partículas sólidas ainda dispersas.

7 - reservação: para finalizar, a água cinza tratada, denominada água recuperada, é conduzida para a desinfecção por meio da adição de cloro.

\section{Sistema de reservação de água não potável}

Após o tratamento da água cinza, a água recuperada é conduzida a um reservatório inferior, com capacidade de $10 \mathrm{~m}^{3}$ de efluente tratado.

Desse reservatório a água é bombeada para dois reservatórios superiores, sendo um em cada torre, com capacidade de $9 \mathrm{~m}^{3}$. Dos reservatórios superiores, a água recuperada é conduzida para a coluna de água não potável que alimenta as descargas das bacias sanitárias e as torneiras de jardins, no pavimento térreo.

Figura 7 - Esquema da ETAC com as etapas para tratamento da água cinza
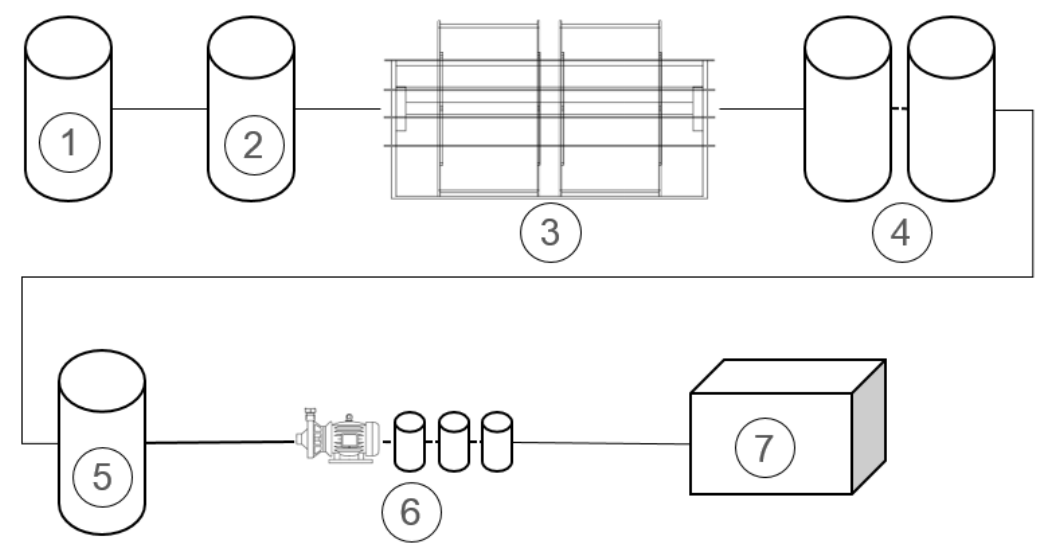


\section{Procedimentos para evitar a contaminação da água potável}

O condomínio não dispõe de procedimentos que contribuem para evitar a contaminação de água potável como, por exemplo, manual ou cartilha com informações técnicas que apresentem os riscos inerentes ao sistema e com práticas de operação e manutenção para gestores, operadores e usuários. Existem, também, algumas tubulações de água não potável que não estão com a sua cor característica para identificação, nesse caso com a cor roxa.

\section{Contaminação no sistema de água potável}

O sistema de água não potável (SPANP-R) projetado e instalado no condomínio operou normalmente no período de julho de 2010 a outubro de 2012. Durante o mês de outubro de 2012 constatou-se que o sistema de água não potável havia contaminado o sistema de água potável do edifício.

A Tabela 1 apresenta os resultados da análise da qualidade da água, coletada em 14/10/2012, após a ocorrência de um surto de infecção gastrointestinal nos moradores do condomínio. A análise foi realizada pela Companhia de Saneamento Básico do Estado de São Paulo (SABESP) com o emprego do método Standard Methods for the Examination of Water and Wasterwater (SMEWW) (AMERICAN...; AMERICAN...; WATER..., 2005).

Observa-se pela Tabela 1 que a amostra coletada no hidrômetro principal do edifício apresenta resultados em atendimento aos valores de referência, recomendados pela Portaria no 2914 do Ministério da Saúde (BRASIL, 2011). Entretanto, as amostras coletadas nos filtros de água dos apartamentos das Torres 1 e 2 apresentaram valores de coliformes totais fora dos padrões exigidos pela Portaria no 2914. Estima-se que mais de 100 moradores apresentaram sintomas relacionados a infecção gastrointestinal.

Por meio de inspeções nas instalações para identificar a causa da contaminação, foi constatada a existência de uma conexão cruzada nos barriletes das duas torres. Havia uma ligação entre o sistema de distribuição de água potável e o sistema de distribuição de água não potável, realizada por meio de uma válvula gaveta. Quando da indisponibilidade de água não potável no sistema, era necessária a abertura manual dessa válvula para alimentar os pontos de água não potável com água potável. No entanto, essa alternância manual de abastecimento do sistema de água não potável deve ser realizada por meio de separação atmosférica e não por meio de ligação direta entre as duas fontes de água.

Nas Figuras 8 e 9 são ilustradas a interligação entre os dois sistemas no barrilete. A tubulação de cor roxa pertence ao sistema de água não potável, e a tubulação de cor verde ao sistema de água potável. Os dois sistemas foram conectados por meio de uma válvula gaveta, que foi substituída pela conexão "tê" com um "cap" na tubulação de água potável, após a ocorrência da contaminação. A Figura 8 mostra uma representação gráfica e pode-se observar que a tubulação de água não potável está posicionada em cota superior à tubulação de água potável, outro procedimento não recomendado.

Após a contaminação, o condomínio realizou a limpeza de todos os reservatórios dos sistemas de água potável e de água não potável. Um mês após a contaminação, uma segunda coleta para avaliar a qualidade da água mostrou que o sistema de água potável do condomínio atendia aos critérios de potabilidade da Portaria no 2914 (BRASIL, 2011). Mesmo assim, o sistema de água não potável foi desativado em maio de 2014, após 13 meses desde a contaminação.

Tabela 1 - Resultados da análise da qualidade da água potável após surto de infecção gastrointestinal nos moradores do condomínio

\begin{tabular}{|c|c|c|c|c|c|c|}
\hline & \multicolumn{3}{|c|}{ Amostras } & \multirow{2}{*}{$\begin{array}{l}\text { Valor de } \\
\text { referência }\end{array}$} & \multirow{2}{*}{$\begin{array}{l}\text { Unidade de } \\
\text { medida }\end{array}$} & \multirow{2}{*}{ Método } \\
\hline & Cavalete & Torre 1 & Torre 2 & & & \\
\hline $\begin{array}{l}\text { Cloro } \\
\text { residual livre }\end{array}$ & 0,54 & $<0,01$ & $<0,01$ & 0,20 a 2,00 & $\mathrm{mg} / \mathrm{L}$ & $\begin{array}{c}\text { SMEWW 21 Ed } \\
4500-O \text { G }\end{array}$ \\
\hline Turbidez & 0,77 & 0,66 & 0,69 & 5,00 & NTU & $\begin{array}{c}\text { SMEWW } 21^{\mathrm{a} E d} \\
21308\end{array}$ \\
\hline $\begin{array}{l}\text { Coliformes } \\
\text { totais }\end{array}$ & Ausente & 1,0 & 1,0 & Ausente & NMP/100 mL & $\begin{array}{c}\text { SMEWW 21 }{ }^{\mathrm{a}} \mathrm{Ed} \\
92238\end{array}$ \\
\hline E. Coli & Ausente & Ausente & Ausente & Ausente & NMP/100 mL & SMEWW 21 ${ }^{\mathrm{a}} \mathrm{Ed}$ \\
\hline
\end{tabular}

Fonte: Companhia de Saneamento Básico de São Paulo (2012). 
Figura 8 - Ligação no barrilete entre água não potável e água potável antes da contaminação

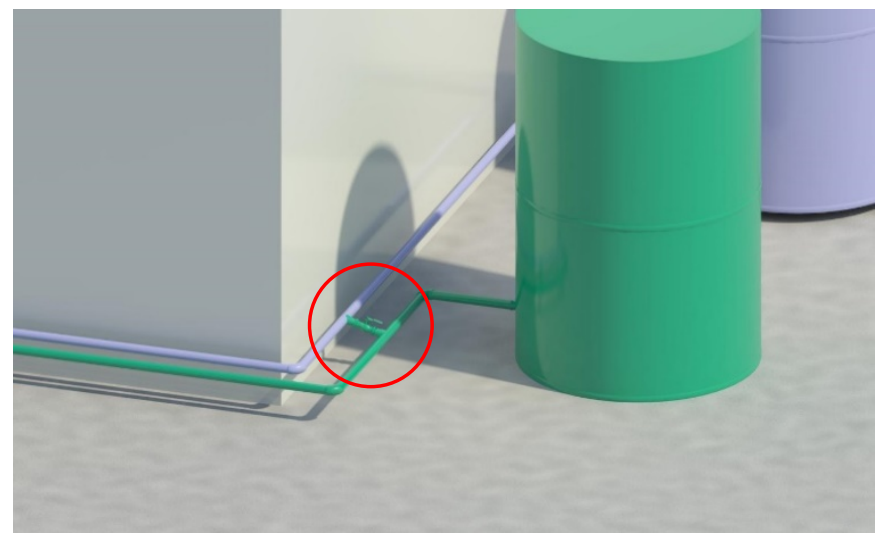

Figura 9 - Ligação no barrilete entre água não potável e água potável após a contaminação

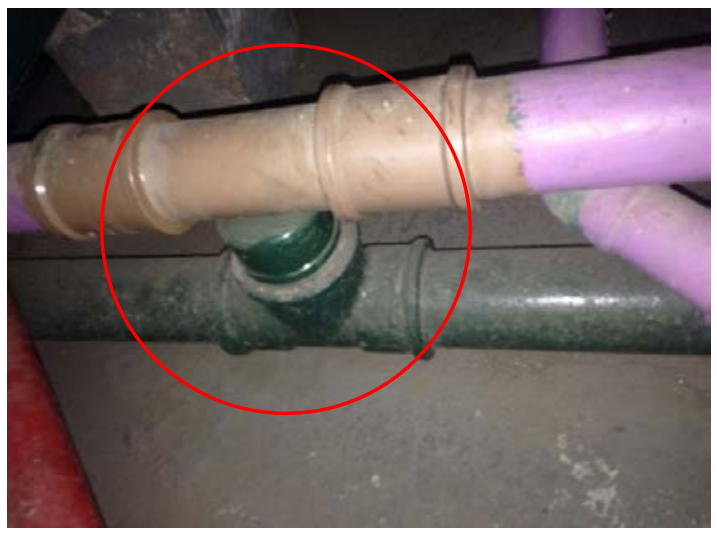

\section{Impactos no consumo de água potável}

No total, foi obtido o consumo de 86 meses, com média mensal de 2697,0 $\mathrm{m}^{3}$. O valor médio do indicador de consumo foi de $151 \mathrm{~L} /$ hab.dia.

Nas Figuras 10, 11, 12 e 13 são apresentados os indicadores de consumo e os consumos mensais de cada fase estudada.

A partir dos dados mostrados nas Figuras 10, 11, 12 e 13, algumas considerações devem ser feitas antes da sua análise:

(a) o condomínio é habitado por uma grande população universitária que, em geral, desocupa os apartamentos durante o período de férias, meses de janeiro e dezembro;

(b) considerando-se que a ocorrência de ocupações e desocupações de apartamentos é frequente, pode-se afirmar que o perfil de consumo de água é dinâmico durante todo o espaço amostral temporal; e

(c) nas informações coletadas, o início e fim de uma determinada fase teve ordem de grandeza de meses, durante o período de tempo estudado. Assim, pode haver um pequeno erro intrínseco, na ordem de grandeza de dias, que não interfere na análise em um contexto maior.

A fase 1 foi denominada fase inicial do período de uso e operação do condomínio, sem o sistema de água não potável. Em geral, durante os primeiros meses há muitos apartamentos desocupados, o que explica o baixo consumo nos meses de janeiro e fevereiro de 2009. Foi durante essa fase que foi observado o mês com maior consumo da série histórica, ou seja, de 3819,0 $\mathrm{m}^{3}$. O indicador de consumo durante essa fase foi de 158,5 L/hab.dia.

A fase 2 foi marcada pela instalação e operação do sistema de água não potável - recuperada, e também pela ocorrência da contaminação do sistema de água potável. Pode-se dividir essa fase em duas subfases: antes da contaminação e após a contaminação. No geral, incluindo as duas subfases, o indicador de consumo foi de 156,8 L/hab.dia. Comparando-se as médias das fases 1 e 2, verifica-se uma redução de aproximadamente $1 \%$ do consumo mensal médio, valor irrelevante. 
Figura 10 - Indicador de consumo e consumo mensal de água na fase 1

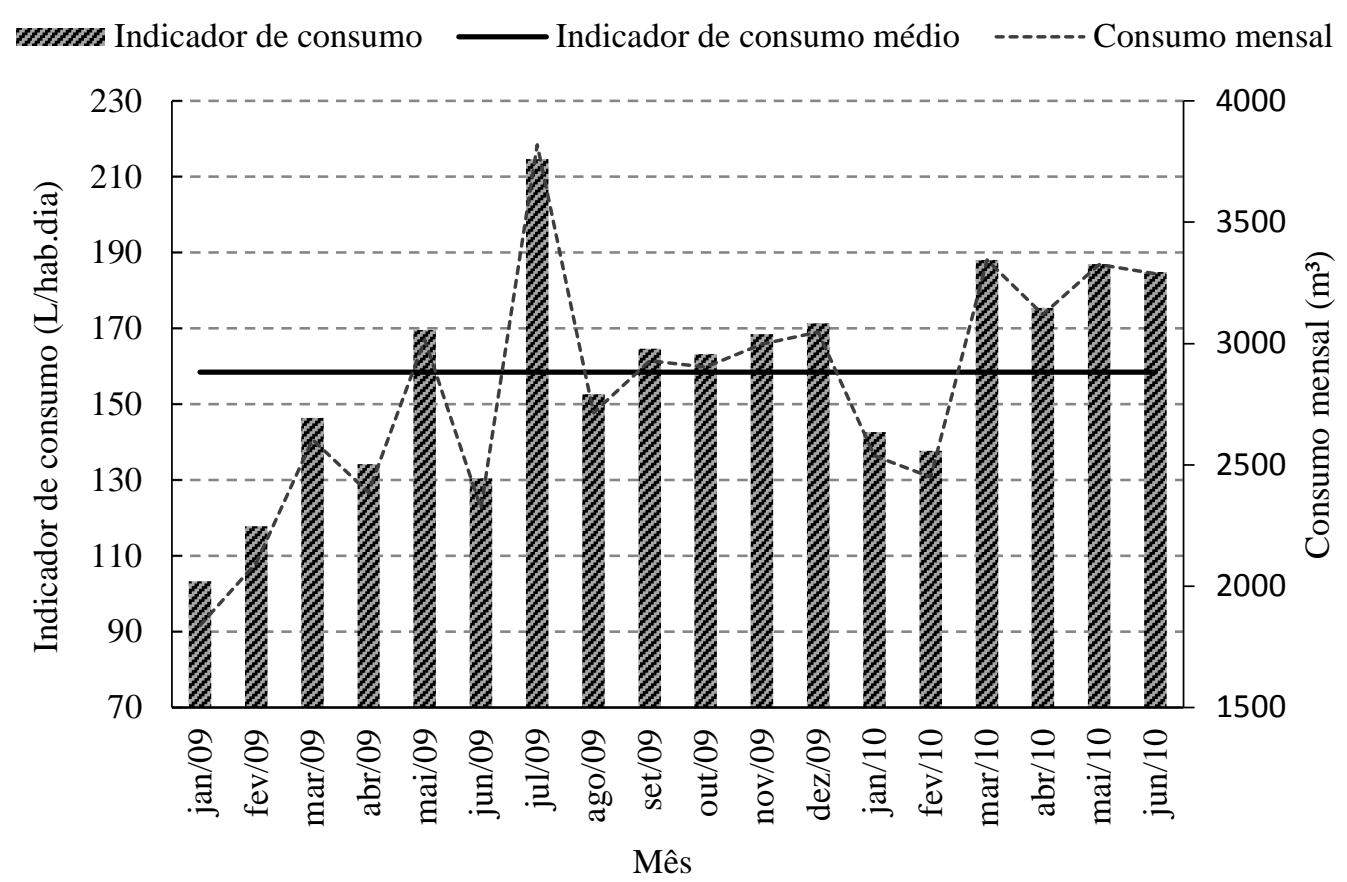

Figura 11 - Indicador de consumo e consumo mensal de água na fase 2

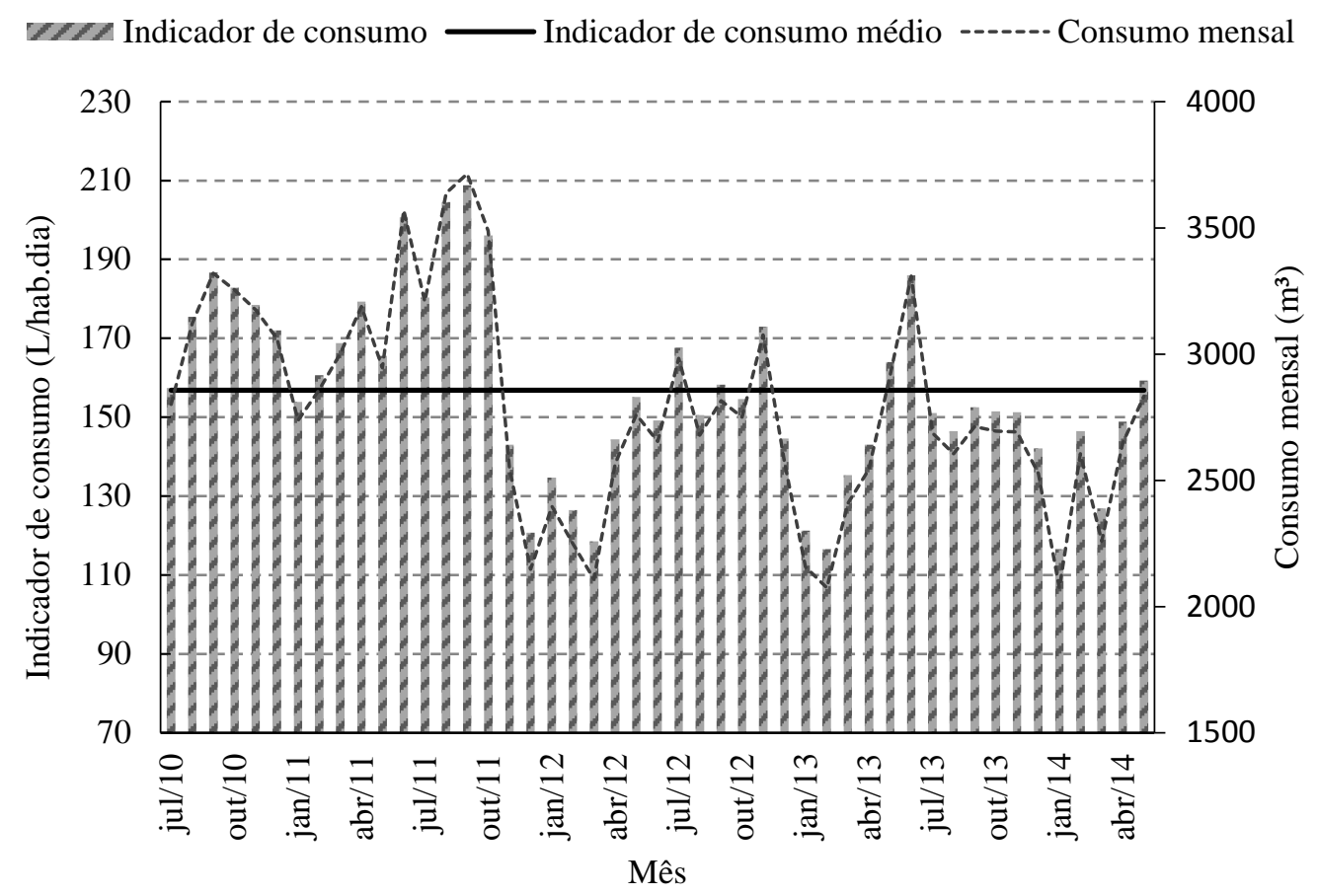


Figura 12 - Indicador de consumo e consumo mensal de água na fase 3

Indicador de consumo __ Indicador de consumo médio ------- Consumo mensal

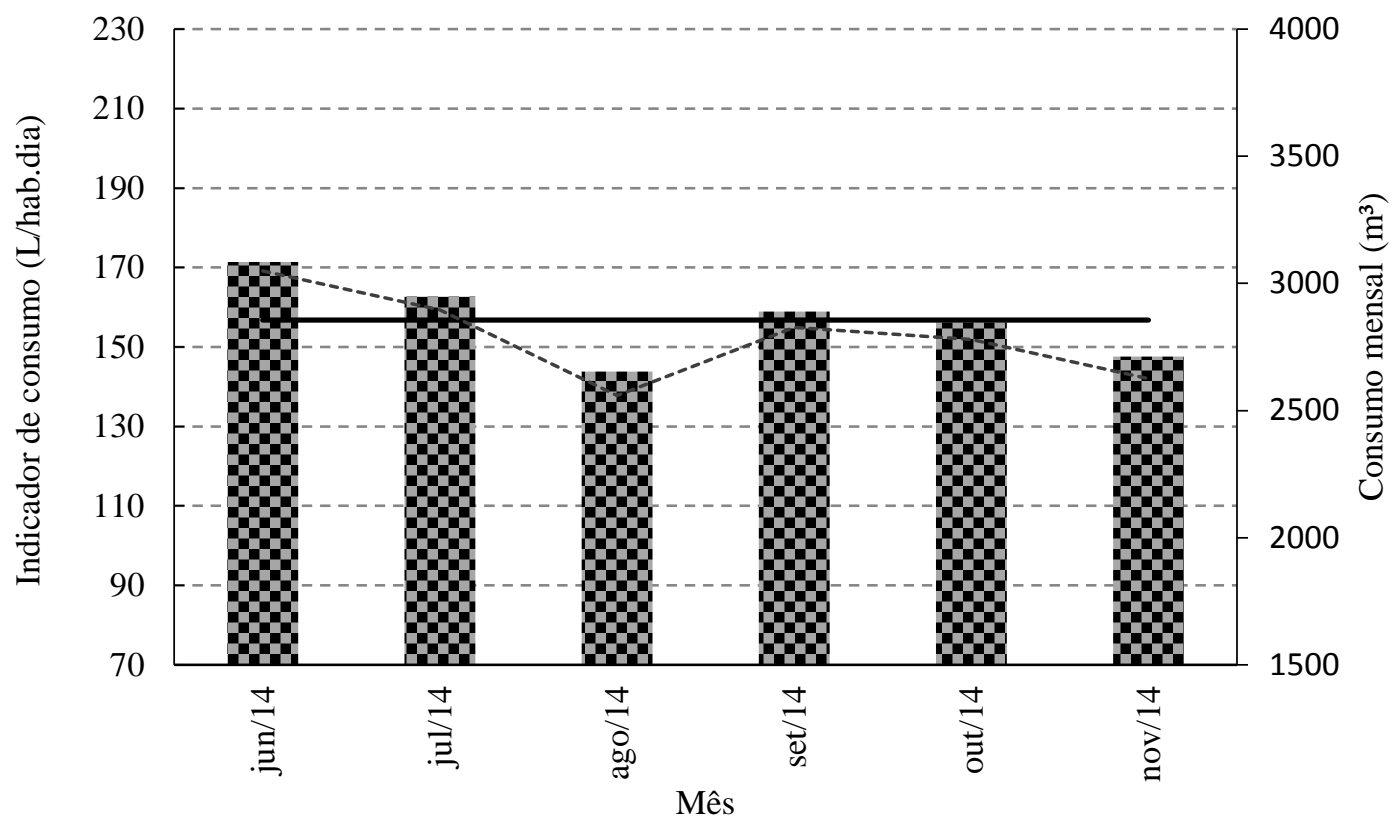

Figura 13 - Indicador de consumo e consumo mensal de água na fase 4

L----- Indicador de consumo —_ Indicador de consumo médioa ------- Consumo mensal

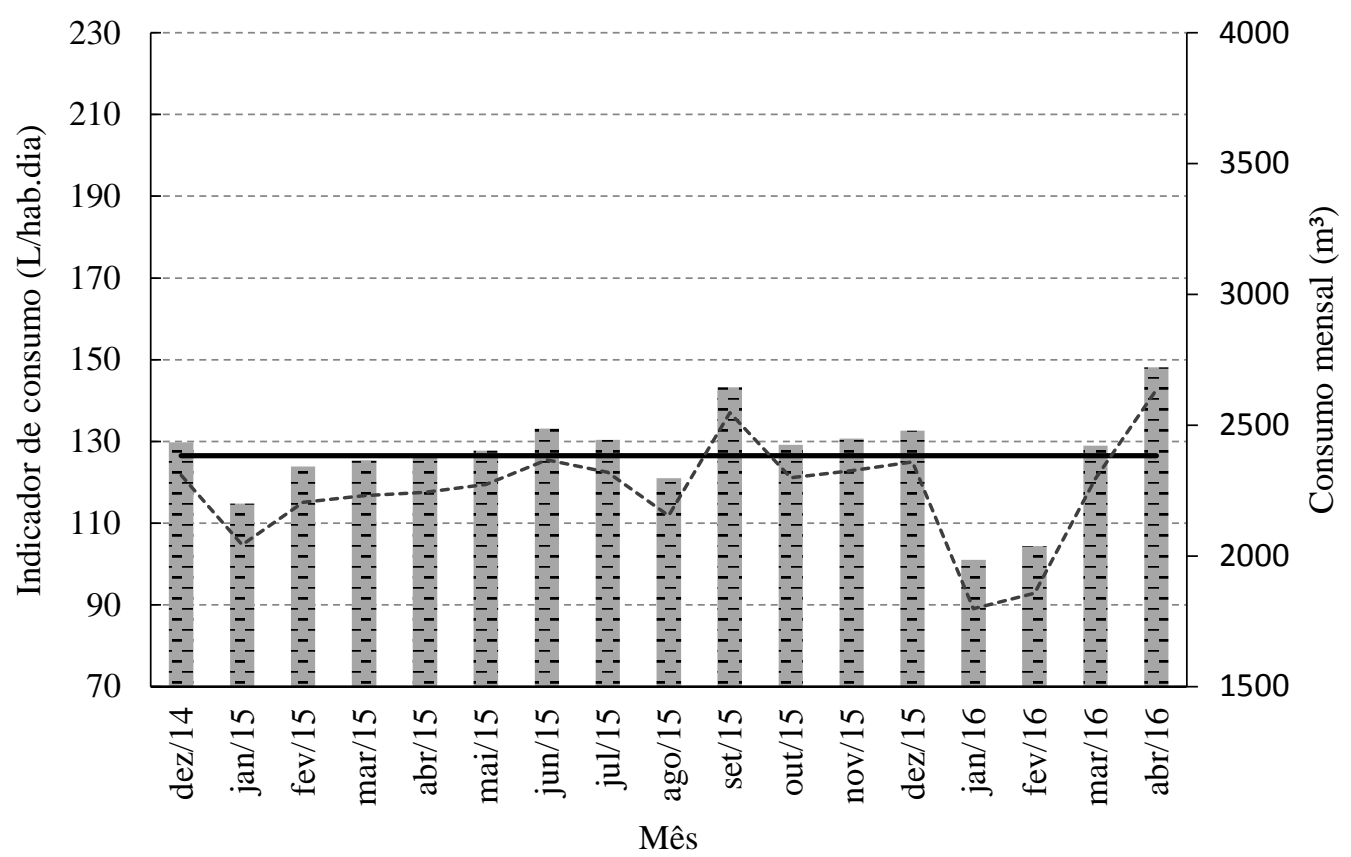

Ainda na fase 2, antes da ocorrência da contaminação em setembro de 2012, o indicador de consumo foi de 164,4 L/hab.dia. Após a contaminação, o indicador de consumo foi de
144,7 L/hab.dia. Desse modo, observa-se um impacto de redução de $12 \%$ do consumo de água após a ocorrência da contaminação. Esse dado aponta para uma possível mudança de hábito dos 
usuários em relação ao uso da água fornecida pela concessionária. A água utilizada em atividades que exigem potabilidade, como a água que é utilizada para cozinhar e a água para consumo, pode ter sido substituída por água mineral.

Em seguida, com o sistema de água não potável desativado durante a fase 3 , obteve-se um indicador de consumo de 156,8 L/hab.dia. Esse valor ficou idêntico ao da média calculada durante toda a fase 2, ou seja, de 156,8 L/hab.dia. Contudo, quando comparado com o indicador de consumo após a contaminação durante a fase 2 , verifica-se que o indicador de consumo dessa fase teve um aumento de 7,7\%, um indício de que os usuários voltaram a utilizar a água potável para todas as atividades.

A fase 4 foi estabelecida a partir da utilização de outras fontes de água não potável - água subterrânea e água pluvial. O período apresentou um indicador de consumo de 126,5 L/hab.dia, o melhor resultado da série histórica apresentada. Verifica-se um impacto de redução de 19,3\% quando comparada com a fase 2, com água não potável - recuperada, e 19,3\% quando comparada à fase 3 , sem água não potável.

Supõe-se que o principal motivo para esse impacto de redução no consumo é o fato de coincidir com a crise hídrica ocorrida no Estado de São Paulo entre os anos de 2014 e 2015, especialmente na região metropolitana de São Paulo. Assim, o estabelecimento de metas de consumo de água pela concessionária local, além de campanhas de conscientização relacionadas ao uso da água, pode ter influenciado a redução do consumo. Outro fato relevante é que a água utilizada na lavagem das garagens e nos jardins internos do condomínio durante essa fase foi proveniente das fontes de água subterrânea e de água pluvial.

Os valores de indicador de consumo verificados em cada uma das fases estudadas estão ilustrados na Figura 13.

Observa-se na Figura 14 que o indicador consumo do condomínio permanece próximo durante as três primeiras fases, com média de 157,4 L/hab.dia e desvio padrão de 0,78 L/hab.dia. Ressalta-se que a última fase apresenta indicador de consumo de 126,5 L/hab.dia.

Esses resultados evidenciam que não houve impacto de redução de consumo de água no condomínio durante as três primeiras fases, mesmo com a implantação do sistema de água não potável - recuperada. Todavia, com a melhoria da gestão do uso da água, durante o período de escassez, além da utilização de água pluvial e de água subterrânea para alguns fins específicos, pode-se verificar impacto de redução de 19,5\% no consumo médio.

\section{Figura 14 - Indicadores de consumo de água nas fases analisadas}

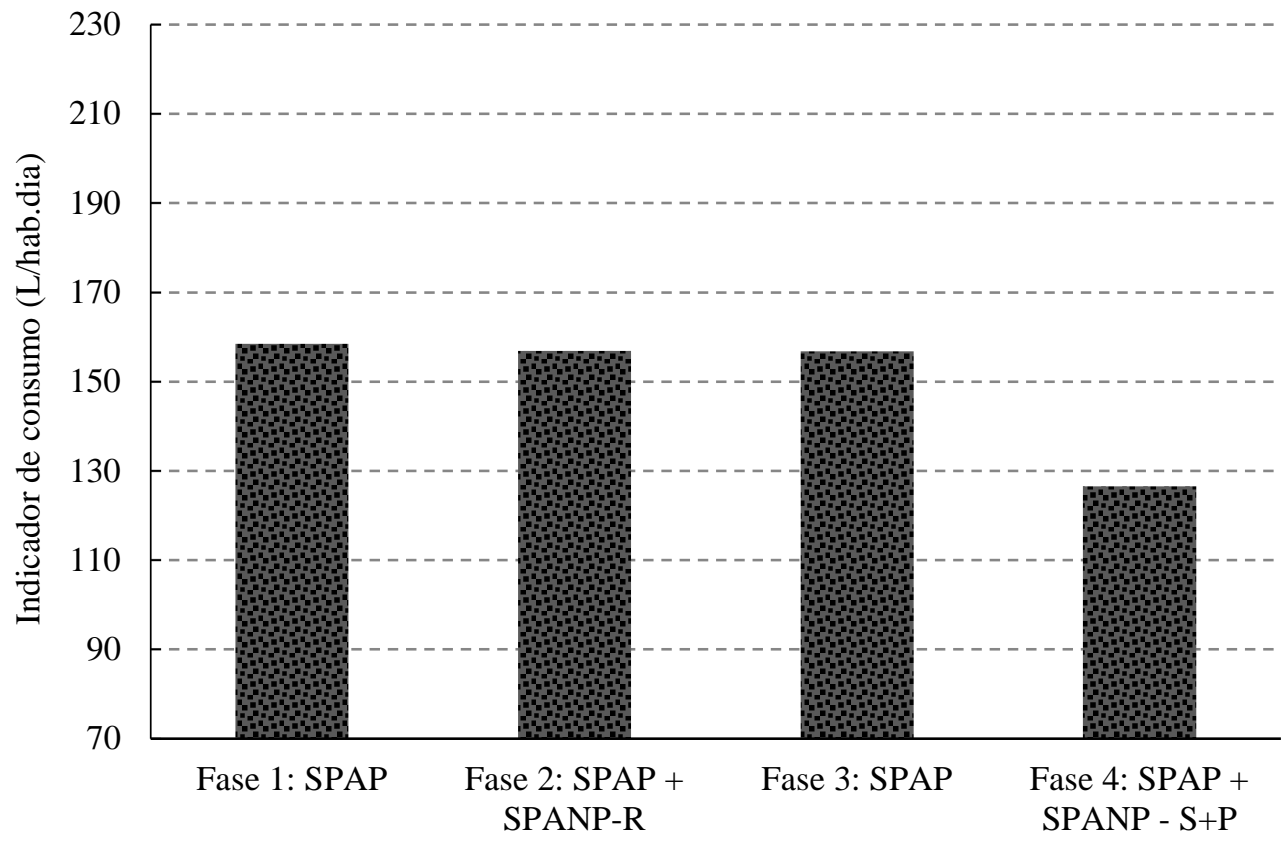

390 Ferreira, T. de V. G.; Oliveira, L. H. de. 


\section{Conclusões}

Em geral, o principal impacto esperado pelos usuários, quando da implantação de um sistema predial de água não potável, é aquele relacionado ao aspecto quantitativo: a redução do consumo de água. No entanto, nesse caso, o maior impacto foi quanto ao aspecto qualitativo, ou seja, a contaminação da água potável pela conexão cruzada no barrilete, fato que prejudicou a saúde de cerca de 100 usuários por meio de um surto de infecção gastrointestinal.

Com relação ao consumo de água, observa-se que o maior impacto de redução do consumo foi verificado no período de escassez, quando os usuários tiveram que gerenciar o uso da água. Ressalta-se que o valor do indicador de consumo praticamente não variou nas três primeiras fases, ou seja, sem água não potável, com água não potável - recuperada e sem água não potável, com um valor médio de 157,4 L/hab.dia, enquanto na fase 4, com a escassez de água e água não potável pluvial e subterrânea, o impacto de redução é de 19,5\% em relação às três fases anteriores.

Com relação à qualidade da água, os aspectos relevantes que colocam em risco a saúde dos usuários são: comunicação visual do sistema de água não potável inadequada, pois somente parte da tubulação é pintada de roxo; operação e manutenção realizada por profissional não capacitado, o que propiciou a execução da conexão cruzada; falta de controle da qualidade da água, além de usuários mal informados, dada a inexistência de um manual ou cartilha sobre o SPANP, além de informações em reuniões de condomínio.

Observa-se que a falta de capacitação técnica, normas técnicas e legislações específicas que orientem projetistas, executores, gestores e usuários e padronizem os sistemas prediais de água não potável contribui para colocar em risco a saúde dos usuários. Ressalta-se que a NBR 5626 (ABNT, 1998), mesmo sendo para sistema predial de água fria, poderia ter sido empregada na questão relacionada à separação atmosférica como meio mais efetivo de evitar o refluxo.

Assim, este estudo de caso evidencia que a segurança dos usuários de sistemas de água não potável em edifícios depende da gestão da qualidade que, por sua vez, aumenta a responsabilidade do síndico do condomínio. Em acréscimo, ressalta-se que a ausência de gestão da qualidade da água pode colocar a saúde dos usuários em risco e a ausência de gestão da quantidade impossibilita a análise de impacto de redução do consumo de água.

\section{Referências}

AMERICAN PUBLIC HEALTH

ASSOCIATION; AMERICAN WATER WORKS

ASSOCIATION; WATER ENVIRIONMENTAL

FEDERATION. Standard Methods for the

Examination of Water and Wastewater. $21^{\text {st }} \mathrm{ed}$. American Public Health Association, 2005.

ASSOCIAÇÃO BRASILEIRA DE NORMAS

TÉCNICAS. NBR 5626: instalação predial de água fria. Rio de Janeiro, 1998.

BRASIL. Ministério da Saúde. Portaria no 2914, de 12 de dezembro de 2011, que dispõe Sobre os Procedimentos de Controle e Vigilância da Qualidade da Água Para Consumo Humano e Seu Padrão de Potabilidade.

BRASIL. Ministério de Minas e Energia. Plano Nacional de Energia 2030. Colaboração Empresa de Pesquisa Energética. Brasília: MME; EPE, 2007.

COMPANHIA DE SANEAMENTO BÁSICO DE SÃO PAULO. Base de dados de fornecimento de água da cidade de São Paulo. Disponível em: <site.sabesp.com.br> Acesso em: 15 jan. 2016.

COMPANHIA DE SANEAMENTO BÁSICO DE SÃO PAULO. Resultados de Ensaios de

Amostra de Água. Divisão de Controle Sanitário e Sistemas Isolados Oeste, 2012.

DIMITRIADIS, S. Issues Encountered in Advancing Australia's Water Recycling Schemes. Parliamentary Library - Information analysis and advice for the Parliament, v. 2, 2005.

DIXON, A. M.; BUTLER, D.; FEWKES, A. Guidelines For Greywater Re-Use: health issues. Water and Environment Journal, v. 13, p. 322326, 1999.

ENVIRONMENT AGENCY. Greywater for Domestic Users: an information guide. May, 2011. Disponível em: <http://cdn.environmentagency.gov.uk/geho0511btwc-e-e.pdf $>$. Acesso em: jul. 2012.

FEARNSIDE, P. M. Greenhouse Gas Emissions From Brazil's Amazonian Hydroelectric Dams. Environmental Research Letter, v. 11, 2016.

FRIEDLER, E.; KOVALIO, R.; GALIL, N. I. OnSite Greywater Treatment and Reuse in MultiStorey Buildings. Water Science \& Technology, v. 51, n. 10, p. 187-194, 2005.

HERNÁNDEZ, F. et al. Feasibility Studies for Water Reuse Projects: an economical approach. Desalination, v. 187, p. 253-261, 2006. 
OLIVEIRA, L. H. O Uso de Água Não-Potável em Edifícios Residenciais. Hydro, São Paulo, v. 34, p. 60-63, 2009.

OLIVEIRA, L. H; MARQUES, I. G. Padronização de Conceitos de Sistemas Prediais de Água Não Potável. Hydro, São Paulo, v. 82, p. 64-69, 2013.

PARSONS, D. et al. The Perceived Barriers to the Inclusion of Rainwater Harvesting Systems by UK House Building Companies. Urban Water Journal, v. 4, n. 7, p. 257-265, 2010.

PEIXOTO, L. M. Requisitos e Critérios de Desempenho Para Sistema de Água Não Potável de Edifícios Residenciais. São Paulo, 2008. Dissertação (Mestrado em Engenharia Civil) Escola Politécnica, Universidade de São Paulo, São Paulo, 2008.
SCHEE, W. G. van der. Experiences with a Collective Domestic Water System in Leidsche Rijn. In: SYMPOSIUM WATER SUPPLY AND DRAINAGE FOR BUILDINGS, Paris, 2004. Proceedings... São Paulo: USP, 2004.

SHEHABI, A.; STOKES, J.R.; HORVATH, A. Energy and Air Emission Implications of a Decentralized Wastewater System.

Environmental Research Letters, California, v. 7, n. 2, 2012.

SHIMIZU, Y.; DEJIMA, S.; TOYOSADA, K. $\mathrm{CO}_{2}$ Emission Factor for Rainwater and Reclaimed Water Used in Building in Japan. Water, v. 5, p. 394-404, 2013.

\section{UNITED STATES ENVIRONMENTAL} PROTECTION AGENCY. Primer for Municipal Wastewater Treatment Systems. Washington: Office of Wastewater Management and Office of Water, 2004.

\section{Tiago de Vasconcelos Gonçalves Ferreira}

Departamento de Engenharia de Construção Civil, Escola Politécnica | Universidade de São Paulo| Av. Prof. Almeida Prado, 83, Trav. 1, Cidade Universitária | São Paulo - SP - Brasil | CEP 05508-000 | Tel.: (11) 3091-5458 | E-mail: tiagovasconcelos@usp.br

\section{Lúcia Helena de Oliveira}

Departamento de Engenharia de Construção Civil, Escola Politécnica | Universidade de São Paulo | E-mail: lucia.helena@usp.br

\section{Revista Ambiente Construído}

Associação Nacional de Tecnologia do Ambiente Construído

Av. Osvaldo Aranha, 99 - 3o andar, Centro

Porto Alegre - RS - Brasil

CEP $90035-190$

Telefone: +55 (51) 3308-4084

Fax: +55 (51) 3308-4054

www. seer. ufrgs. br/ ambienteconstruido

E-mail: ambienteconstruido@ufrgs.br 